\title{
STUDENTS' PERCEPTION OF A TERM PROJECT WITH RESPECT TO TECHNICAL CONCEPTS UNDERSTANDING, CREATIVE THINKING AND INTEREST IN PROGRAMMING IN A LARGE, FLIPPED DELIVERY INTRODUCTORY PROGRAMMING COURSE - A CASE STUDY
}

\author{
Katherine Dornian, Robyn Paul, Sepideh Afkhami Goli, Ioana Rontu, and Mohammad Moshirpour \\ Schulich School of Engineering, University of Calgary \\ katherine.dornian@ucalgary.ca
}

\begin{abstract}
The Computing for Engineers (ENGG 233), first year programming class uses a 3-week end term project to involve students in a technical, creative and applicable project. In Fall 2018, students designed and programmed a new digital dashboard, displaying information such as current speed and fuel level based on sensory inputs such as engine revolutions per minute, gear ratio, and car position in the horizontal and vertical axis. A student perception survey was distributed and analyzed to better understand the view that students have towards term projects. The results from a Kendall Tau-B test are presented in this paper.
\end{abstract}

Keywords: flipped learning : project-based learning : Kendall Tau-B : first-year engineering : computing

\section{INTRODUCTION}

Engineering industry is always evolving, and we need to ensure that our post-secondary institutions are evolving as well in order to prepare our graduates for their future careers. The graduate attributes defined by the Canadian Engineering Accreditation Board (CEAB) include a wide variety of skillsets, including technical mastery, as well as professional skills such as communication, teamwork, and project management [9]. In order to promote deep learning of the technical content, while still fostering professional skills, we have used an approach that blends flipped learning with project-based learning pedagogies.

The flipped course delivery method allows students to spend the appropriate level of time needed for their level of skill, while also being held accountable by weekly milestones such as online quizzes [27, 29]. Additionally, project-based learning is a pedagogical technique that engages students in investigations in search of answers to significant questions and requires them to produce a tangible artifact representing a solution to the complex problems initially posed [1]. In this paper we specifically discuss a flipped project-based learning approach to a mandatory first-year engineering course at the University of Calgary with approximately 850 students. The course is designed to cater to students with varying levels of programming knowledge and ability, while it aims to spark students' interest in software engineering. After flipped learning classes throughout the term, a project is introduced with weekly milestones during the last three weeks of the term. For the project, students are provided with a real-life problem and the opportunity to apply the newly learned programming skills in delivering a solution.

The objective of this paper is to better understand students' perceptions and views of flipped learning and project-based learning in a first-year programming course. We provide the results from two analyses of an end-of-term survey sent to all students enrolled in the course in Fall 2018. Using Kendall Tau-B tests, we gain insight into students' perceptions of the term project, and students' overall views regarding programming.

\section{LITERATURE REVIEW}

Since 2012, the CEAB has required institutions to demonstrate they are fostering the 12 graduate attributes in their students [9]. This outcomes-based approach to accreditation has changed the landscape of engineering education. Over the last decade, there has been significant increases in the quantity and quality of educational research in engineering [8]. Engineering educators are now actively seeking out pedagogies that are founded in best 
practices in order to foster essential skills in our students. Two pedagogies that are commonly applied in engineering are the flipped learning model and project-based learning. There is a significant amount of practice-based and research-based literature that has been published on both these topics. We summarize some high-level ideas here to provide context for our approach.

\subsection{Flipped Learning Model}

Flipped learning gives students the opportunity to learn at their own pace by moving instructional content to videos and media (usually delivered through an online learning platform) to be watched outside of class and using class time for hands-on activities and discussion [23, 26]. Flipped learning in engineering education is relatively new, having seen increased adoption since 2012, although others have been using it since the early 2000s [19]. Students' perceptions have generally been positive and benefits such as flexibility, increased interaction, and improved student engagement have been widely observed [3]. Recent meta-analysis has shown strong evidence that student achievement also improves as compared to a traditional lecture approach $[17,25]$.

The style is not without its challenges, careful design of content is required from instructors in order to maximize learning $[5,19]$. While flipped learning classes generally improve student engagement, students who initially lack interest in the content or are unfamiliar with the style may not engage as readily [6]. Furthermore, learning course material from an out-of-class environment does not enable immediate question answering as in a traditional classroom [6], on the other hand, the material is conducive to review and self-pacing on the student's end [25]. Other critics draw attention to technological challenges for both students and instructors [5].

All of this suggests that more research into the practice and methodological implementation by the instructors is required in order to implement successful flipped classrooms. With several years of academic critique, best practices to promote student engagement and achievement are available $[3,19,25]$.

In the case of engineering course projects, improvements to student outcomes can be seen as well as benefits such as increasing instructor interaction [18, 24].

\subsection{Project-Based Learning}

Project-based learning gives students an opportunity to apply and build their competencies through a contextual project $[7,21,27]$. For engineering education, it offers the benefits of engaging students and helping them to understand applications of the knowledge [27]. It also gives students the opportunity to develop important professional skills beyond the topic at hand, such as project management, communication, creativity, and teamwork $[20,31]$. As with the flipped classroom model, effective implementation of project-based learning must be facilitated by an educator with an understanding of the learning process in order to set students up for success [20, 21].

Although project-based learning has been around for somewhat longer than the flipped classroom, reports on its benefits are still mixed [14, 27], however, improved motivation, retention, and skill development have been widely reported on [21]. Adding to the difficulty of accessing effectiveness is the fact that project-based learning in engineering education has various implementations that make it difficult to track impact and define clear best practices [14].

\section{METHOD AND ANALYSIS}

There are two parts to this study. The first part investigates the relationships between students' perceptions regarding term projects with respect to the technical understanding, creativity, and interest in programming. The second part of this study explores relationships between the perception students have and the overall view they hold with regard to (1) enjoyment of computer programming, (2) interest in software engineering, (3) finding computer programming difficult, and (4) the perception that programming is an important skill for engineers.

\subsection{Method}

A voluntary 25 question "Google Form" survey was sent to all students enrolled in the Fall 2018 course, approximately 850 students. This study will only focus on a select seven questions that related to the scope of this study. Respondents were anonymous and the overall response rate was about $60 \%$. No demographic or grade information was collected, only the lecture section the student was registered in was documented. The survey used a five-point Likert-scale [4] with values of strongly disagree, disagree, neutral, agree, strongly agree to measure level of agreement for each of the 24 statements included in the survey. A sixth answer was available to students, "N/A", however those responses were removed from the data set at the beginning of the statistical analysis, leaving 512 data points.

The first four questions were related specifically to the group projects and the last four were general questions regarding student views of programming related topics:

Term project student perceptions: 
Q1 (Tech) My understanding of technical concepts increased

Q2 (Creat) My creative thinking was improved

Q3 (Inter) My interest in programming increased

General student perceptions:

Q4 (Enjoy) I enjoy computer programming

Q5 (Career) I am interested in a career in software engineering

Q6 (Diffic) I find computer programming difficult

Q7 (Import) I think programming is an important skill for engineers

\subsection{Data Analysis}

The five-point Likert answer scale was converted to a numerical value from one to five, with strongly disagree being a one and strongly agree a five.

Due to the ordinal nature of the data collected and the large number of tied ranks, we chose to use the non-parametric correlation, Kendall's Tau-B for data analysis $[11,15]$. Our Kendall's Tau-B tests hypotheses follows the general hypothesis typically used in statistical testing. We use this hypothesis for each comparison test of two variables presented in the results:

$$
\begin{gathered}
H 0: \tau_{b}=0 \text {, the two variables are independent, there no } \\
\text { monotonic relationship. }
\end{gathered}
$$

$H A: \tau_{b} \neq 0$, the two variables are not independent, there is a monotonic relationship.

The Kendall Tau-B test determines the monotonic relationship, strength and direction, as well as the significance between two independent variables. A monotonic relationship is simply defined as a relationship between two variables, where (1) as one variable increases the other one also increases or (2) whereas one variable increases, the other variable decreases. Literature indicates that Kendall Tau-B correlation strength tends to be similar or slightly lower than the alternative non-parametric test, Spearman's correlation, due to a different scale being used $[11,13,15]$. To check this, we calculated both the Kendall Tau-B and Spearman's correlation coefficients. From this calculation, we found that for all 22 statistical tests performed for this study, the Kendall Tau-B values were consistently lower than the Spearman's, as literature suggests. On average, the Kendall Tau-B correlation coefficient was lower by 0.0441 than Spearman's coefficient. To analyze the strengths of the results obtained, the literature recommends a value of $|0.7|$ or higher indicates strong for Kendall Tau-B [15]. There was less clear guidance as to interval ranges for medium and weak correlation strengths, for the purpose of analysis in this study, a medium correlation is considered as being $\geq$ $|0.3|$ and a weak correlation is considered as being $\geq|0.1|$. A correlation close to 0 indicates there is no monotonic relationship between the two variables.

We checked the three assumptions of using Kendall's Tau-B as follows [1]:

1) The two variables must be continuous or ordinal.

2) The two variables are paired samples.

3) Data follows monotonic relationship. This is not a strict assumption.

The third assumption is not strict because Kendall's Tau-B correlation determines only monotonic relationships, hence if the data does not exhibit this, the correlation number will be close to zero, indicating that a monotonic relationship does not exist.

The statistical analysis was performed using IBM's SPSS Statistics Software.

\section{CASE STUDY DESCRIPTION}

At the University of Calgary, ENGG 233: Computing for Engineers is a mandatory introductory programming course for first-year students taken during the Fall semester. In the past few years, enrollment numbers have reached approximately 850 students each fall semester [26]. In July 2015 , the course delivery method was changed from traditional lecture style to flipped learning, to increase student hands-on opportunities with an instructor [26]. At the same time, the programming language was changed from $\mathrm{C}++$ to Processing [12], a Java-based language which allows novice students to produce visual outputs. This change was implemented to emphasize applied learning and algorithmic thinking [26].

The course focuses on exposing students with various levels of programming abilities to concepts such as selection and loop structures, functions, arrays and data records, and object-oriented programming. Each week, students watch approximately 100-minutes of YouTube videos broken down into manageable portions before attending two in-person sessions: a 75-minute lecture and 110-minute laboratory. The videos incorporated online quizzes worth $10 \%$ of the students' final grade and were designed to help students stay on track and assess their understanding of the content.

During the lectures, instructors demonstrate examples and students had the opportunity to ask questions. Laboratories were used for students to work through assignments with the help of a teaching assistant. Students were expected to submit the in-lab assignments by the end of the laboratory session. In addition, students submitted a post-lab assignment a week after their lab session. Assignments were worth $20 \%$ of the students' final grade. 
Table 1: Ratings for Survey Questions

\begin{tabular}{cccccccccc}
\hline \hline Likert Scale (\%) & \multicolumn{10}{c}{ Strongly } \\
Agree & Total Number of \\
Question & $\begin{array}{c}\text { Strongly } \\
\text { Disagree } \\
(1)\end{array}$ & $\begin{array}{c}\text { Disagree } \\
(2)\end{array}$ & $\begin{array}{c}\text { Neutral } \\
(3)\end{array}$ & $\begin{array}{c}\text { Agree } \\
(4)\end{array}$ & $\begin{array}{c}\text { Mean } \\
\text { Responses }\end{array}$ & SD & Mode \\
\hline Q1 Tech & $2 \%$ & $4 \%$ & $12 \%$ & $55 \%$ & $27 \%$ & 510 & 4.01 & 0.853 & 4 \\
Q2 Creat & $3 \%$ & $6 \%$ & $15 \%$ & $49 \%$ & $28 \%$ & 509 & 3.94 & 0.936 & 4 \\
Q3 Inter & $8 \%$ & $15 \%$ & $19 \%$ & $34 \%$ & $23 \%$ & 510 & 3.49 & 1.234 & 4 \\
\hline Q4 Enjoy & $7 \%$ & $10 \%$ & $16 \%$ & $37 \%$ & $30 \%$ & 510 & 3.72 & 1.200 & 4 \\
Q5 Career & $17 \%$ & $20 \%$ & $23 \%$ & $20 \%$ & $19 \%$ & 509 & 3.06 & 1.365 & 3 \\
Q6 Diffic & $7 \%$ & $19 \%$ & $24 \%$ & $34 \%$ & $17 \%$ & 510 & 3.35 & 1.164 & 4 \\
Q7 Import & $1 \%$ & $3 \%$ & $16 \%$ & $47 \%$ & $34 \%$ & 509 & 4.09 & 0.832 & 4 \\
\hline \hline
\end{tabular}

Note: $S D=$ Strongly Disagree, $D=$ Disagree, $N=$ Neutral, $A=$ Agree, $S A=$ Strongly Agree

Students used the last three laboratory sessions during the Fall 2018 course offering to work on their term project, which spanned the last three weeks of the term. Students were expected to apply concepts previously learned throughout the course such as classes, arrays and functions to complete the project. Furthermore, the project aimed to introduce students to designing and developing a relatively large software product, teaching them how to break it down into manageable portions and to practice version control. Lastly, students were exposed to teamwork and were expected to present their progress at the intermediate and final milestone delivery.

The project entailed a scenario-based problem, where students were tasked with writing the code and designing a user interface dashboard for a new consumer car. Students had the choice of completing the project individually or with a partner. The final program took four inputs: rotations per minute (rpm), fuel level, gear ratio, and car coordinates to calculate six metrics: speed, travelled distance, fuel level, consumption, economy, and range. The calculated metrics were to be displayed on a vehicle dashboard in a creative manner. To incentivize creative thinking, bonus points were awarded to students for creative visualization, historical data display, and extra features/functionalities.

To ensure students were making progress and to enforce the concept of iterative design, one intermediate milestone was set during the second week of the project, where students were expected to demonstrate a simplistic looking dashboard, displaying the speed, RPMs and fuel level calculations. The second and final milestone required students to demonstrate the final product with all the features. The project was worth $10 \%$ of the students' final grade.

\section{RESULTS/FINDINGS}

\subsection{Data Characteristics}

Table 1 above displays the student response percentage breakdown. Additionally, the mean, standard deviation and mode for the data was included.

The discrepancy between the number of responses for some of the questions above and the total number of responses received for the whole survey (512) is due to some students not answering all questions.

\subsection{Kendall Tau-B Results Q1 - Q3}

For the first part of this study, Kendall's Tau-B correlation was performed among the three term-project related questions to identify whether any significant relationships can be identified (Table 2).

Table 2: Kendall Tau-B Significant Results Q1-3

\begin{tabular}{|c|c|c|c|}
\hline $\mathbf{Q}$ & Q1-Tech & Q2-Creat & Q3-Inter \\
\hline Q1 & & & \\
\hline Q2 & $\begin{array}{c}\tau_{\mathrm{b}}=0.631 \\
s i g=0.0005 \\
\mathrm{~N}=509\end{array}$ & & \\
\hline Q3 & $\begin{array}{c}\tau_{\mathrm{b}}=0.456 \\
\text { sig }=0.0005 \\
\mathrm{~N}=510\end{array}$ & $\begin{array}{c}\tau_{\mathrm{b}}=0.483 \\
s i g=0.0005 \\
\mathrm{~N}=509\end{array}$ & \\
\hline
\end{tabular}

The findings indicate that as a students' technical understanding increases, so does their creative ability, showing a statistically significant medium, positive association, $\tau_{\mathrm{b}}=+0.631, \mathrm{p}=0.0005$. Likewise, as technical understanding increased, interest in programming increased, showing a statistically significant medium, positive association, $\tau_{b}=+0.456, p=0.0005$. Finally, we see that as creativity increased, interest in the subject 
increased, again, showing a statistically significant medium, positive association, $\tau_{\mathrm{b}}=+0.483, \mathrm{p}=0.0005$. Given these results, the first part of this study shows that there is positive relationship among technical understanding, creativity and interest in programming.

\subsection{Kendall Tau-B Results Q4 - Q7}

Next, the relationships between the students' perceptions on the term project and general perspectives on enjoying computer programming, interest in software engineering, finding computer programming difficult and the belief that programming is an important skill for engineers were explored (Table 3).

Table 3: Term Project: Kendall Tau-B Results Q4-7

\begin{tabular}{|c|c|c|c|}
\hline $\mathbf{Q}$ & Q1-Tech & Q2-Creat & Q3-Inter \\
\hline $\begin{array}{c}\text { Q4 } \\
\text { Enjoy }\end{array}$ & $\begin{array}{c}\tau_{\mathrm{b}}=0.390 \\
\operatorname{sig}=0.0005 \\
\mathrm{~N}=509\end{array}$ & $\begin{array}{c}\tau_{\mathrm{b}}=0.398 \\
\operatorname{sig}=0.0005 \\
\mathrm{~N}=508\end{array}$ & $\begin{array}{c}\tau_{\mathrm{b}}=0.594 \\
\operatorname{sig}=0.0005 \\
\mathrm{~N}=509\end{array}$ \\
\hline $\begin{array}{c}\text { Q5 } \\
\text { Career }\end{array}$ & $\begin{array}{c}\tau_{\mathrm{b}}=0.246 \\
\operatorname{sig}=0.0005 \\
\mathrm{~N}=508\end{array}$ & $\begin{array}{c}\tau_{\mathrm{b}}=0.242 \\
\operatorname{sig}=0.0005 \\
\mathrm{~N}=507\end{array}$ & $\begin{array}{c}\tau_{\mathrm{b}}=0.479 \\
\operatorname{sig}=0.0005 \\
\mathrm{~N}=508\end{array}$ \\
\hline $\begin{array}{c}\text { Q6 } \\
\text { Diffic }\end{array}$ & $\begin{array}{c}\tau_{\mathrm{b}}=-0.186 \\
\text { sig }=0.0005 \\
N=509\end{array}$ & $\begin{array}{c}\tau_{\mathrm{b}}=-0.178 \\
\operatorname{sig}=0.0005 \\
\mathrm{~N}=508\end{array}$ & $\begin{array}{c}\tau_{\mathrm{b}}=-0.269 \\
\operatorname{sig}=0.0005 \\
\mathrm{~N}=509\end{array}$ \\
\hline $\begin{array}{c}\text { Q7 } \\
\text { Import }\end{array}$ & $\begin{aligned} \tau_{\mathrm{b}} & =0.269 \\
\operatorname{sig} & =0.0005 \\
\mathrm{~N} & =509\end{aligned}$ & $\begin{array}{c}\tau_{\mathrm{b}}=0.276 \\
\operatorname{sig}=0.0005 \\
\mathrm{~N}=507\end{array}$ & $\begin{array}{c}\tau_{\mathrm{b}}=0.355 \\
\operatorname{sig}=0.0005 \\
\mathrm{~N}=508\end{array}$ \\
\hline & $\begin{array}{l}\text { Positive } m \\
\text { Positive } w \\
\text { Negative } 1\end{array}$ & $\begin{array}{l}\text { Legend: } \\
\text { dium correlatio } \\
\text { ak correlation } \\
\text { eak correlation }\end{array}$ & \\
\hline
\end{tabular}

The results show a medium, positive association existing between the view that the term project increased technical understanding and the general view that computer programming is enjoyable, which was statistically significant, $\tau_{\mathrm{b}}=+0.390, \mathrm{p}=0.0005$. A medium, positive association was found between the views that creative thinking improved, and enjoyment of computer programming increased, which was statistically significant, $\tau_{\mathrm{b}}=+0.398, \mathrm{p}=0.0005$. We also see statistically significant medium, positive associations between views that the term project increased their interest and their enjoyment of programming $\left(\tau_{\mathrm{b}}=+0.594, \mathrm{p}=\right.$ $0.0005)$, their interest in a software engineering career $\left(\tau_{\mathrm{b}}\right.$ $=+0.479, \mathrm{p}=0.0005)$, and the view that programming is an important skill for engineers $\left(\tau_{b}=+0.355, p=0.0005\right)$. Other weak, positive associations were found around term project perceptions and career aspirations as well as the importance of programming. Negative, weak associations were found between the perceptions of the term project and the difficulty of programming.

\subsection{Discussion}

The first part of the study regarding perceptions of the term project shows a positive relationship between technical understanding, creativity, and interest. The finding that technical understanding has a relationship with creativity is interesting and under-researched in the field of engineering education, however, research in arts education has shown significant positive correlation between technical skill and creativity [30], which aligns with our result. While the importance of creativity (often referred to as innovation) in engineering is championed by many scholars [16, 31, 33], methods for developing and teaching creativity in engineering are less clear [34]. However, our findings support that projectbased learning in engineering education improves creativity.

Our findings from the first part also support the argument that technical understanding and interest are mutually supported [28, 32]. It is unclear from our results whether interest drives technical understanding or vice versa; the previous research cited suggests that it could act both ways, with interest driving learning and previous knowledge driving interest. This result could be used to build a case for the integration of project-based learning into flipped classrooms, as lack of interest in a topic can cause disengagement in such classrooms [6]. Overall, our findings from this part of the study indicate that projectbased learning is a way to engage engineering students' and develop their creativity alongside their technical understanding. Further research could look more closely at the relationship and interactions of these perceptions.

The results from the second part of the study support what we would hope to find in an engineering classroom: as students' perception of their technical understanding, creative thinking, and interest increased, other general perceptions like enjoyment of the topic, career aspirations toward the discipline, and importance of the topic improved, while their perception of difficulty decreased.

Some of the strongest correlations in the second part are seen around interest in programming as a result of the term project and the general student perceptions of programming. The implication of this finding is that creating interesting content for students is valuable and can be done with projects. Project-based learning offers this opportunity by allowing students to explore what interests them and produce an artifact that combines their technical and non-technical skills with their interests [27].

The next strongest correlations were seen in general enjoyment of programming and perceived benefits of the term project on student abilities. This reflects findings from other research, such as that by Ainley and Ainley [2], that 
found a strong association between enjoyment and interest, as is seen in our study. The crucial inference we can make is that the interest in the term project increased enjoyment of programming generally. That is, by providing an interesting project that develops technical and creative skills we can improve the general enjoyment of the subject, i.e. computer programming. Given existing research, such as that by Ainley and Ainley, we should expect that this enjoyment leads to higher re-engagement with programming for students later. Further longitudinal research could be conducted to investigate and verify this phenomenon.

From these results, we can infer that a term project in a large, flipped classroom offers an opportunity for engineering students to develop technical and creative skills as well as enjoyment and interest in the subject.

\section{LIMITATIONS}

In this study, students' self-reported data are quantified to understand the correlations between technical understanding, enjoyment and affinity towards the subject. However, students' ability to judge their own comprehension of subject matter is limited [10, 22]. If this phenomenon occurs in our study, the validity of the results could come into question. Because this study did not link term grades to responses or other achievement assessments, we are unable to produce a more accurate measure of how technical competence improved. Furthermore, the survey did not define terms such as 'technical concepts' and 'creative thinking'. This leaves it up to each individual student to determine an individual meaning and score for the questions.

Anecdotal evidence and responses were not analyzed in this study but could offer more insight into the changing attitudes of students over the semester of the ENGG 233 course. This information can provide useful, albeit unquantifiable, context for such programs that can guide future design of courses and projects.

Finally, students could work on the term project individually or with a partner. This information was not collected in the survey. This variable could shed light on the advantages or disadvantages of teamwork compared to individual work in term projects. Without tracking this information, we assume all students had a similar experience with the project. As a result, the effects of this difference cannot be measured or reported on.

\section{CONCLUSION}

This paper provides a description of how we integrated flipped-learning and project-based learning into a large first-year engineering course. Project-based learning allows students to simultaneously develop technical understanding, creativity, and interest. Furthermore, their heightened interest improves other perceptions like their enjoyment of the topic, the subject's value, and their career aspirations in the field. Further research in this area aims to conduct qualitative analysis in order to better understand the features of the course that are most impactful for developing these skills in students and look at the longterm impacts of the term project on student's engagement with computer programming.

\section{References}

[1] "Basic requirements of Kendall's Tau-B," in https://statistics.laerd.com/premium/spss/ktb/kendallstau-b-in-spss-3.php, 31-May-2019 (accessed).

[2] Mary Ainley and John Ainley, "Student engagement with science in early adolescence: The contribution of enjoyment to students' continuing interest in learning about science," Contemporary Educational Psychology, vol. 36, no. 1, pp. 4-12, 2011.

[3] Gökçe Akçayır and Murat Akçayır, "The flipped classroom: A review of its advantages and challenges," Computers \& Education, vol. 126, pp. 334-345, 2018.

[4] I. Elaine Allen and Christopher A. Seaman, "Likert scales and data analyses," Quality Progress, pp. 6465, 2007.

[5] Sara Arnold-Garza, "The flipped classroom teaching model and its use for information literacy instruction," Communications in Information Literacy, vol. 8, no. 1, pp. 7-22, 2014.

[6] Jonathan Bergmann and Aaron Sams, "Flip your classroom: Reach every student in every class every day," International Society for Technology in Education, 2012.

[7] Phyllis C Blumenfeld, et al., "Motivating projectbased learning: Sustaining the doing, supporting the learning," Educational psychologist, vol. 26, no. 3-4, pp. 369-398, 1991.

[8] Robert Brennan, et al., "A systematic review of Canadian engineering education research 2004-2017," in 2018 Canadian Engineering Education Association (CEEA-ACEG-ACEG18) Conf., (University of British Columbia; 3-6 June 2018), 1-5 pp., 2018.

[9] Canadian Engineering Accreditation Board, Accreditation Criteria and Procedures 2016. Engineers Canada, 2017.

[10] David Dunning, Chip Heath, and Jerry M. Suls, "Reflections on self-reflection: Contemplating flawed self-judgements in the clinic, classroom, and office cubicle," Perspectives on Psychological Science, vol. 13, no. 2, pp. 185-189, 2018. 
[11] Andy Field, Discovering Statistics Using IBM SPSS Statistics. Sage, 2013. \{ISBN: 1446274586\}

[12] Ben Fry and Casey Reas, "Processing.org - Cover," in https://processing.org/, 25 January 2019 (accessed).

[13] Jan Hauke and Tomasz Kossowski, "Comparison of values of Pearson's and Spearman's correlation coefficients on the same sets of data," Quaestiones geographicae, vol. 30, no. 2, pp. 87-93, 2011.

[14] Laura Helle, Päivi Tynjälä, and Erkki Olkinuora, "Project-Based learning in post-secondary education theory, practice and rubber sling shots," Higher Education, vol. 51, no. 2, pp. 287-314, 2006.

[15] Dennis R Helsel and Robert M Hirsch, Statistical methods in water resources. Elsevier, 1992. \{ISBN: 0444885285 \}

[16] International Engineering Alliance, 25 Years of the Washington Accord. 2004.

[17] Marnie V. Jamieson, et al., "The University of Alberta chemical engineering capstone design course goes flipped!," in 2015 Canadian Engineering Education Association (CEEA15) Conf., (McMaster University; 31 May - 3 June 2015), 6 pp., 2015.

[18] Marnie Vegessi Jamieson and John M. Shaw, "Student and instructor satisfaction and engagement with blended learning in chemical engineering design," in 2017 Canadian Engineering Education Association (CEEA17) Conf., (Toronto; 4-7 June 2017), 8 pp., 2017.

[19] Aliye Karabulut-Ilgu, Nadia Jaramillo Cherrez, and Charles T. Jahren, "A systematic review of research on the flipped learning method in engineering education," British J. of Educational Technology, vol. 49, no. 3, pp. 398-411, 2018.

[20] Dimitra Kokotsaki, Victoria Menzies, and Andy Wiggins, "Project-based learning: A review of the literature," Improving Schools, vol. 19, no. 3, pp. 267277, 2016.

[21] Anette Kolmos and Erik de Graaff, "Problem-based and project-based learning in engineering education," Cambridge Handbook of Engineering Education Research, pp. 141-161, 2014.

[22] Vicki Langendyk, "Not knowing that they do not know: self-assessment accuracy of third-year medical students," Medical Education, vol. 40, no. 2, pp. 173179, 2006.

[23] Lina Lee, "Active learning," in The SAGE Encyclopedia of Educational Research, Measurement, and Evaluation, B. B. Frey (eds.), Thousand Oaks:
SAGE Publications, Inc, $201839-40$ pp. \{ISBN: 9781506326153\}

[24] Evan C. Lemley, et al., "Implementing a flipped classroom in thermodynamics," in 120th ASEE Annu. Conf. \& Exposition, (Atlanta, USA; 23-26 June 2013), 8 pp., 2013.

[25] Chung Kwan Lo and Khe Foon Hew, "The impact of flipped classrooms on student achievement in engineering education: A meta-analysis of 10 years of research," Journal of Engineering Education, vol. 108, no. 4, pp. 523-546, 2019.

[26] Emily Ann Marasco, Mohammad Moshirpour, and Mahmood Moussavi, "Flipping the foundation: A multi-year flipped classroom study for a large-scale introductory programming course," in ASEE Annu. Conf., (Columbus, USA; 25-28 June), 9 pp., 2017.

[27] Julie E. Mills and David F. Treagust, "Engineering education - is problem-based or project-based learning the answer?," Australasian Journal of Engineering Education, 2014.

[28] K Ann Renninger, "Individual interest and development: Implications for theory and practice," The role of interest in learning and development, vol. 26, no. 3-4, pp. 361-395, 1992.

[29] Ioana Rontu, et al., "Framework for teaching parallel flipped classrooms," in 2019 Canadian Engineering Education Association (CEEA-ACEG19) Conf., (Ottawa; 9-12 June 2019), 5 pp., 2019.

[30] Susan M. Rostan, "Educational Intervention and the Development of Young Art Students' Talent and Creativity," Educational Intervention and the Development of Young Art Students' Talent and Creativity, vol. 39, no. 4, pp. 237-261, 2005.

[31] W. B. Stouffer, Jeffrey S. Russell, and Michael G. Oliva, "Making the strange familiar: Creativity and the future of engineering education," in American Society for Engineering Education Annual Conference \& Exposition, 13 pp., 2004.

[32] Sigmund Tobias, "Interest, Prior Knowledge, and Learning," Review of Educational Research, vol. 64, no. 1, pp. 37-54, 1994.

[33] US National Academy of Engineering, The Engineer of 2020: Visions of Engineering in the New Century. Washington, DC: The National Academies Press, 2004, 53-57 pp. \{ISBN: 978-0-309-09162-6\}

[34] Sarah Zappe, Irene Mena, and Thomas Litzinger, "Creativity is Not a Purple Dragon," in OPEN 2013: NCIIA's 12th Annual Conference, (Washington, USA; 22-23 March 2013), 13 pp., 2013. 